\title{
PENGARUH KEPEMIMPINAN DAN MOTIVASI TERHADAP KINERJA KARYAWAN FOOD \& BEVERAGE DEPARTMENT HOTEL ARYADUTA LIPPO VILLAGE, TANGERANG
}

\author{
Arlingka Herlambang HR*); Sonny \\ Universitas Pamulang \\ *)email: lingkalambang@gmail.com
}

\footnotetext{
Paper Accepted: 24 Maret 2021 Paper Reviewed: 25-31 Maret 2021 Paper Edited: 01-15 April 2021 Paper Approved: 25 April 2021
}

\begin{abstract}
ABSTRAK
Penelitian ini bertujuan untuk megetahui Pengaruh Kepemimpinan dan Motivasi Kerja Terhadap Kinerja Karyawan baik secara parsial maupun secara simultan Pada Food \& Beverage Department Hotel Aryaduta Lippo Village Tangerang. Metode penelitian yang digunakan adalah Deskriptif Kuantitatif dengan Populasi 133 Orang dan Sampel sebanyak 57 Responden dengan Uji Analisis Data sebagai berikut : Uji Validitas, Uji Reliabilitas, Uji Koefisien Korelasi, Uji Regresi Linear Sederhana Dan Berganda, Koefisien Determinasi, Uji t dan Uji F. Berdasarkan hasil perhitungan analisis regresi berganda diperoleh $\mathrm{Y}=16,892+0,307 \mathrm{X} \_1+0,236 \mathrm{X} \_2$, ini berarti bahwa Kepemimpinan (X_1) dan Motivasi (X_2) berpengaruh positif terhadap Kinerja Karyawan (Y), Kepemimpinan memberikan nilai pengaruh sebesar 0,307 dan Motivasi memberikan nilai pengaruh sebesar 0,236 terhadap Kinerja Karyawan dengan asumsi variabel lain tetap. Hasil penelitian Koefisien Determinasi diperoleh sebesar 0,266 atau 26,6\%, hal ini menunjukan bahwa 26,6\% Kinerja Karyawan dipengaruhi oleh variabel Kepemimpinan dan Motivasi, sedangkan sisanya sebesar 73,4\% dipengaruhi oleh variabel lain. Dari hasil penelitian ini menunjukan bahwa variabel Kepemimpinan terhadap Kinerja Karyawan berpengaruh signifikan, hal tersebut dapat dilihat dari Uji t nilai hitung sebesar 3,823>t tabel sebesar 1,673 dengan nilai signifikan dan variabel Motivasi terhdap Kinerja Karyawan berpengaruh signifikan, hal tersebut dapat dilihat dari Uji t nilai hitung sebesar 3,638>t tabel sebesar 1,673. Hasil penelitian dari Kepemimpinan dan Motivasi secara bersama - sama berpengaruh terhadap Kinerja Karyawan dari hasil perhitungan didapatkan angka Uji $\mathrm{F}$ hitung sebesar 9,807 > F tabel sebesar 2,780 dengan nilai signifikan $0,000<0,05$ maka H_0 ditolak dan H_a diterima. Dari hasil tersebut dapat disimpulkan bahwa Kepemimpinan dan Motivasi mempunyai pengaruh signifikan secara parsial dan simultan terhadap Kinerja Karyawan.
\end{abstract}

Kata Kunci: Kepemimpinan, Motivasi, Kinerja Karyawan

\section{PENDAHULUAN}

\section{Latar Belakang}

Manajemen adalah sebuah proses dalam mengatur segala sesuatu yang dilakukan oleh sekelompok orang atau organisasi demi mencapai tujuan dengan cara bekerja sama dengan memanfaatkan semua sumber daya yang dimiliki. Sumber Daya Manusia adalah salah satu faktor yang sangat penting yang tidak dalpat dilepaskan dari sebuah kelompok ataupun organisasi yang merupakan kunci penentu perkembangan didalam suatu perusahaan.

Perusahaan sangat bergantung pada kemampuan sumber daya manusia yang dimiliki, untuk memanfaatkan sumber daya yang ada didalam perusahaan demi menjalankan tugas - tugas kerja dalam kerangka kerja yang terarah untuk pengembangan organisasi. 
Keberhasilan seluruh pelaksana tugas - tugas kerja didalam suatu perusahaan sangat bergantung oleh ketersediaan sumber daya manusia yang berkualitas, dengan harapan besar untuk dapat berperan aktif sebagai perencana pelaksanaan sekaligus sebagai pengawas terhadap semua kegiatan manajemen perusahaan. Tidak hanya peningkatan kualitas sumber daya manusia, pihak perusahaan pun dituntut untuk meningatkan daya saing melalui peningkatan kualitas manajemen. Oleh karena itu agar perusahaan dapat berkembang secara optimal, maka pemeliharaan hubungan yang selaras dan secara berkelanjutan dengan para karyawan menjadi hal yang sangat penting.

Disinilah perlunya seorang pemimpin dalam perusahaan sebagaimana peran kepemimpinan dalam pengelolaan sumber daya manusia sehingga bias mengintegrasikan antara keinginan perusahaan dengan keinginan karyawan. Dalam hal ini pemimpin memiliki peranan sentral dalam kehidupan organisasi maupun kelompok. Demi mencapai tujuan tujuan bersama, sumber daya manusia didalam organisasi perlu membina kebersamaan dengan mengikuti pengendalian dari pimpinannya. Dengan pengendalian tersebut, perbedaan keinginan kehendak, kemauan, perasaan, kebutuhan, dan lain - lain dipertemukan untuk digerakan ke arah yang sama. Dengan demikian dalam setiap organisasi, perbedaan individual dimanfaatkan untuk mencapai tujuan yang sama sebagai kegiatan didalam kepemimpinan yang akan mempengaruhi suatu motivasi karyawan terhadap kinerja yang akan diberikan karyawan untuk mencapai target atau tujuan perusahaan.

Menurut Edy Sutrisno (2016 : 213), Kepemimpinan adalah suatu proses kegiatan seseorang untuk menggerakan orang lain untuk melakukan sesuatu agar mencapai hasil yang diharapkan. Menurut Hasibuan (2016:170) gaya kepemimpinan merupakan pendorong gairah kerja, kepuasan kerja, dan produktivitas kerja karyawan yang tinggi, agar dapat mencapai tujuan organisasi yang maksimal. Menurut Miftah Thoha (2010 : 9), kepemimpinan adalah kegiatan untuk mempengaruhi perilaku orang lain, atau seni mempengaruhi perilaku manusia baik perorangan maupun kelompok. Atas dasar pengertian diatas dapat disimpulkan bahwa kepemimpinan adalah kemampuan seseorang pemimpin dalam mempengaruhi dan menggerakan seseorang untuk mencapai tujuan organisasi yang telah ditetapkan sebelumnya secara efektif dan efisien.

Karyawan akan merasa termotivasi, dan merasa tindakannya mengarah pada pencapaian tujuan dan imbalan berharga yang akan mengerti keinginan pimpinannya dan akan menyelesaikan tugas nya sesuai dengan yang diinginkan pimpinannya. Dengan tercapainya tujuan maka akan ada imbalan atau bonus seperti imbalan, reward, atau kenaikan jenjang karir yang cukup menjanjikan unutuk kesejahteraan para karyawannya. Menurut penelitian yang dilakukan oleh peneliti, gaya kepemimpinan yang diterapkan dalam Hotel Aryaduta Lippo Village Tangerang kurang tepat terhadap setiap karyawan. Para pemimpin dalam Food \& Beverage Department Aryaduta Lippo Village Tangerang sangatlah senioritas, para pemimpin menekan setiap karyawannya untuk lebih aktif dalam penjualan sehingga target minimal pendapatan department yang telah ditentukan perusahaan dapat terealisasi setiap tahunnya.

Sedangkan masalah yang dihadapi adalah promo yang kurang berjalan karena tidak ada kreatifitas dan pembaruan seperti evaluasi menu baru, harga dan lainnya. Penerapan ide promo untuk mendorong target pendapatan perusahaan seharusnya jobdesk untuk para pemimpin tersebut. Sehingga menimbulkan rasa ketidak nyamanan bagi setiap pekerja yang mempengaruhi motivasi dan kinerja karyawan yang diberikan. Menurut Usmara (2015:014) motivasi adalah suatu kumpulan kekuatan tenaga yang berasal dari dalam maupun luar individu yang memulai sikap dan menetapkan bentuk, arah, serta intensitasnya. Hodgetts dan luthans mengemukakan motivasi sebagai proses psikologis melalui keinginan yang belum terpuaskan, yang diarahkan kepencapaian tujuan / insentif. Toha, Miftah (2015:203) motivasi merupakan salah satu unsur pokok dalam perilaku seseorang.

Motivasi adalah suatu proses pesikologi namun demikian, ini bukan berarti bahwa motivasi adalah satu-satunya unsur yang bisa menjelaskan adanya perilaku seseorang. Maslow dalam Usmara (2015:18) berpendapat bahwa motivasi seseorang adalah memiliki kebutuhan yang mereka perjuangkan untuk dipenuhi, bahwa kebutuhan mereka kompleks, dan bahwa kebutuhan mereka terus menerus berubah. Motivasi menjadi suatu hal penting jika dihubungkan dengan kinerja, oleh karena itu setiap karyawan perlu diberikan motivasi untuk meningkatkan prestasi dalam pekerjaannya. Dengan memotivasi maka akan tumbuh dorongan pada diri karyawan untuk menyalurkan segala usaha daya dan upaya dalam bekerja untuk untuk memperoleh kinerja yang maksimal. Oleh karena itu motivasi sangat penting karena menyangkut kebutuhan individu yang harus sesuai dengan tujuan organisasi, 
motivasi karyawan Food \& Beverage Department Hotel Aryaduta Lippo Village

Menurut Hasibuan (2014:138), "kinerja karywan suatu hasil yang dicapai oleh seseorang dalam melaksanakan tugas-tugas yang dibebankan kepadanya”. Berdasarkan pengertian di atas, maka dapat disimpulkan bahwa kinerja karyawan adalah suatu hasil kerja suatu karyawan dalam suatu proses atau pelaksanaan tugasnya sesuai dengan tanggung jawabnya dan seberapa banyak pengaruhnya terhadap pencapaian tujuan organisasi. Menurut Mangkunegara (2015:128), "kinerja karyawan hasil kerja secara kualitas dan kuantitas yang dicapai oleh seseorang karyawan dalam melaksanakan tugasnya sesuai dengan tanggung jawab yang diberikan kepadanya". Selain itu Smith (2014:196) menjelaskan, "kinerja adalah hasil dari suatu proses yang dilakukan manusia".

Dalam hal ini Hotel Aryaduta Lippo Village Tangerang, sebagai perusahaan yang bergerak dalam bidang Pariwisata yang menjual jasa penginapan, makanan dan minuman serta pelayanan, sudah seharusnya memiliki karyawan yang penuh semangat dan bermotivasi dalam bekerja dan melakukan pekerjaannya secara efektif dan efisien, untuk kemudian pada akhirnya menunjukan produktivitas yang tinggi dalam usaha mewujudkan misi dan tujuan yang telah di tetapkan.

Sehubungan dengan hal di atas, maka motivasi merupakan masalah yang sangat penting dalam suatu perusahaan, karena dapat meningkatkan produktivitas kerja karyawan. Sehingga kemampuan manajemen dalam memberikan motivasi akan sangat menentukan keberhasilan atau kegagalan dalam pencapaian tujuan perusahaan. Menyadari betapa pentingnya motivasi dalam upaya meningkatkan kinerja kerja karyawan ini. Maka Hotel Aryaduta Lippo Village Tangerang, dengan segala keterbatasan yang dimiliki mencoba untuk melaksanakan program tersebut.

\section{Rumusan Masalah}

Berdasarkan identifikasi dan pembatasan, maka rumusan masalah dalam penelitian ini adalah: 1. Bagaimana pengaruh kepemimpinan terhadap kinerja karyawan Food \& Beverage Departement Hotel Aryaduta Lippo Village Tangerang? 2. Bagaimana pengaruh motivasi terhadap kinerja karyawan Food \& Beverage Departement Hotel Aryaduta Lippo Village Tangerang? 3. Bagaimana pengaruh kepemimpinan dan motivasi secara simultan terhadap kinerja karyawan Food \& Beverage Departement Hotel Aryaduta Lippo Village Tangerang?

\section{METODE PENELITIAN}

Jenis penelitian ini asosiatif. Menurut Sugiyono (2017:44) yaitu "penelitian yang bertujuan untuk mengetahui pengaruh atau hubungan antara dua variabel atau lebih". Dengan demikian penelitian asosiatif ini dapat dibangun suatu teori yang berfungsi untuk menjelaskan, meramalkan dan mengontrol suatu gejala. Penelitian ini merupakan studi empiris yang bertujuan untuk menguji pengaruh lingkungan kerja dan disiplin kerja terhadap Kinerja karyawan.

Data yang diperlukan dalam penelitian ini adalah data mengenai kepemimpinan, motivasi terhadap kinerja karyawan. Pengumpulan data meliputi data primer yang diperoleh dari kuisioner, observasi dan studi pustaka. Kemudian mengumpulkan juga data sekunder. Data ini sama pentingnya untuk memeroleh sejumlah informasi yang relevan mengenai variabel-variabel penelitian dan untuk menyederhanakan data yang dikumpulkan, membuat kesimpulan. Pelaksanaan penelitian sendiri berlangsung selama tiga bulan dari Desember 2019 sampai dengan Februari 2020, dengan jumlah responden 57 orang.

\section{PEMBAHASAN}

\section{Profil Singkat Perusahaan}

Hotel Ayaduta Lippo Village terletak di 401 boulevard jendral sudirman, Lippo karawaci 1300 Tangerang, Banten Indonesia. Hotel ini di bangun sejak tahun 1993 dan selesai pada tahun 1994, dan memulai beroprasi pada tanggal 20 september 1994. Awal hotel ini dengan nama Imperial Century Hotel \& Resort yang dimiliki oleh PT. Aryaduta Hotel tbk, dan dikelola Century International hotel pada maeret 2001 Imperial Century \&resort di tunjuk untuk mengelola Imperial Country Club yang terletak di sebelah dengan hotel, dan dimiliki perusahaan yang sama sehingga akhirnya berganti nama menjadi Imperial Aryaduta \& Country Club.

Sejak awal 2003 kontrak managemen Century International Hotel telah berakhir. Imperal Hotel \& Country Club diambil alih secara penuh oleh PT. Aryaduta Hotel tbk, dan 
akhirnya berganti nama menjadi Imperial Aryaduta Country Club sehingga tahun 2009 dan kini nama menjadi hotel Aryaduta Lippo Village. Hotel Aryaduta Lippo Village adalah salah satu hotel bertaraf bintang 5 di kota Tangerang, hotel Aryaduta Lippo Village memiliki beberapa tipe kamar diantaranya : 134 deluxe rooms, 12 business suites, 2 executive suites, 1 presidential suites, 24 cabana deluxe, 24 cabana suites. Hotel Aryaduta Lippo Village juga menyediakan fasilitas seperti : lobby, business centre, sauna, steam room, aroma therapy massage, reflexology, gymnasium, 2 squash courts, 4 indoor badminton courts, 1 indoor dan 4 outdoor tennis courts, table tennis, swimming pool, mini soccer field, jogging track, wall climbing, billiard, panda kids club, team building land, 1000 square meters of meeting space including 2 ballrooms, outside catering service dan juga terdapat 7 bagian bidang pekerjaan di antaranya: human resource department, IT department, acoounting, front office department, food \& beverage department, housekeeping department, security department.

\section{Uji Validitas}

\begin{tabular}{|c|l|c|c|c|}
\hline No & \multicolumn{1}{|c|}{ Item Kuesioner } & $\mathrm{r}_{\text {hitung }}$ & $\mathrm{r}_{\text {tabel }}$ & keputusan \\
\hline 1. & Pimpinan bertanggung jawab dalam menjalankan tugasnya. & 0,652 & 0,263 & Valid \\
\hline 2. & Pimpinan bijaksana dalam menghargai hasil kerja karyawan. & 0,532 & 0,263 & Valid \\
\hline 3. & Pimpinan adil dalam pembagian tugas. & 0,722 & 0,263 & Valid \\
\hline 4. & Pimpinan selalu mengevaluasi hasil kerja karyawan & 0,597 & 0,263 & Valid \\
\hline 5. & Pimpinan bijaksana dalam mengambil keputusan. & 0,531 & 0,263 & Valid \\
\hline 6. & $\begin{array}{l}\text { Pimpinan memberi sanksi terhadap karyawan yang melanggar } \\
\text { peraturan. }\end{array}$ & 0,603 & 0,263 & Valid \\
\hline 7. & Pemimpin konsisten antara perkataan dan perilaku. & 0,461 & 0,263 & Valid \\
\hline 8. & Pimpinan tidak membeda-bedakan antar karyawan. & 0,538 & 0,263 & Valid \\
\hline 9. & Pimpinan selalu memberi semangat kepada karyawan. & 0,656 & 0,263 & Valid \\
\hline 10. & Pimpinan memberi kebebasan berpendapat kepada karyawan. & 0,639 & 0,263 & Valid \\
\hline
\end{tabular}

Tabel 1. Hasil uji validitas variabel XI (kepemimpinan). Sumber: Hasil Olah Data SPSS 20

Berdasarkan tabel 1, dijelaskan bahwa variabel kepemimpinan (X1) diperoleh r-hitung $>$ r-tabel $(0,263)$. Dengan demikian semua item pernyataan kuisioner dinyatakan valid, sehingga pernyataan tersebut berkorelasi signifikan dengan skor total.

\begin{tabular}{|c|l|c|c|c|}
\hline No & \multicolumn{1}{|c|}{ Item Kuesioner } & $\mathrm{r}_{\text {hitung }}$ & $\mathrm{r}_{\text {tabel }}$ & keputusan \\
\hline 1. & Perusahaan adil dalam pembagian insentif. & 0,534 & 0,263 & Valid \\
\hline 2. & Perusahaan konsisten terhadap pembagian insentif. & 0,562 & 0,263 & Valid \\
\hline 3. & Interaksi antar karyawan terjalin dengan baik. & 0,735 & 0,263 & Valid \\
\hline 4. & Adanya kebebasan interaksi antara karyawan dan pimpinan & 0,696 & 0,263 & Valid \\
\hline 5. & $\begin{array}{l}\text { Perusahaan memberikan kesempatan untuk karyawan dalam } \\
\text { mengembangkan potensinya agar lebih maju. }\end{array}$ & 0,709 & 0,263 & Valid \\
\hline 6. & $\begin{array}{l}\text { Perusahaan memberikan program pelatihan karyawan secara } \\
\text { rutin dan bertahap }\end{array}$ & 0,762 & 0,263 & Valid \\
\hline 7. & Perusahaan selalu memberikan reward atas prestasi karyawan. & 0,483 & 0,263 & Valid \\
\hline 8. & $\begin{array}{l}\text { Reward yang diberikan kepada karyawan berprestasi akan } \\
\text { memotivasi kerja karyawan. }\end{array}$ & 0,472 & 0,263 & Valid \\
\hline 9. & $\begin{array}{l}\text { Atasan selalu memberikan pujian apabila ada karyawan yang } \\
\text { menjalankan tugas pekerjaan dengan memuaskan. }\end{array}$ & 0,523 & 0,263 & Valid \\
\hline 10. & $\begin{array}{l}\text { Pujian yang diberikan atasan memotivasi saya untuk bekerja } \\
\text { lebih baik lagi. }\end{array}$ & 0,655 & 0,263 & Valid \\
\hline
\end{tabular}


Tabel 2. Hasil uji validitas variabel X2 (motivasi). Sumber: Hasil Olah Data SPSS 20

Berdasarkan tabel 2, dijelaskan bahwa variabel motivasi (X2) diperoleh r-hitung > rtabel $(0,263)$. Dengan demikian semua item pernyataan kuisioner dinyatakan valid, sehingga pernyataan tersebut berkorelasi signifikan dengan skor total.

\begin{tabular}{|c|c|c|c|c|}
\hline No & Item Kuesioner & $\mathrm{r}_{\text {hitung }}$ & $\mathrm{r}_{\text {tabel }}$ & keputusan \\
\hline 1. & Saya lebih menekankan pada mutu pekerjaan saya. & 0,656 & 0,263 & Valid \\
\hline 2. & $\begin{array}{l}\text { Kualitas hasil kerja yang saya lakukan sesuai dengan cara } \\
\text { kerja yang ditetapkan. }\end{array}$ & 0,552 & 0,263 & Valid \\
\hline 3. & $\begin{array}{l}\text { Kuantitas pekerjaan yang saya lakukan sesuai dengan } \\
\text { harapan / keinginan atasan. }\end{array}$ & 0,713 & 0,263 & Valid \\
\hline 4. & $\begin{array}{l}\text { Kuantitas pekerjaan yang saya lakukan sesuai dengan target } \\
\text { yang diberikan. }\end{array}$ & 0,583 & 0,263 & Valid \\
\hline 5. & Saya selalu menyelesaikan pekerjaan dengan tepat waktu. & 0,502 & 0,263 & Valid \\
\hline 6. & $\begin{array}{l}\text { Saya berani menerima resiko atas apa yang telah saya } \\
\text { kerjakan. }\end{array}$ & 0,591 & 0,263 & Valid \\
\hline 7. & Memberikan kontribusi kepada tim dalam setiap kegiatan. & 0,455 & 0,263 & Valid \\
\hline 8. & $\begin{array}{l}\text { Menerima dan memberikan kritik serta saran yang } \\
\text { membangun kepada sesama rekan kerja. }\end{array}$ & 0,555 & 0,263 & Valid \\
\hline 9. & Membantu pekerjaan rekan kerja yang belum terselesaikan. & 0,578 & 0,263 & Valid \\
\hline 10. & $\begin{array}{l}\text { Mampu memberikan ide kreatif untuk kemajuan } \\
\text { perusahaan. }\end{array}$ & 0,659 & 0,263 & Valid \\
\hline
\end{tabular}

Tabel 3. Hasil uji validitas variabelY (kinerja karyawan). Sumber: Hasil Olah Data SPSS 20

Berdasarkan tabel 3, dijelaskan bahwa variabel kinerja karyawan (Y) diperoleh $\mathrm{r}$ hitung > r-tabel $(0,263)$. Dengan demikian

\section{Uji Reliabilitas}

Pengujian reliabilitas dilakukan terhadap butir pernyataan yang termasuk dalam kategori reliabilitas. Pengujian reliabilitas dilakukan semua item pernyataan kuisioner dinyatakan valid, sehingga pernyataan tersebut berkorelasi signifikan dengan skor total.

dengan cara menguji coba instrument sekali saja, kemudian dianalisis dengan menggunakan metode cronbach alpha.

\begin{tabular}{|l|c|c|c|}
\hline \multicolumn{1}{|c|}{ Varibel } & Cronbatch Alpha & $\begin{array}{c}\text { Standar Cronbatch } \\
\text { Alpha }\end{array}$ & Keputusan \\
\hline Kepemimpinan & 0,794 & 0,60 & Reliabel \\
\hline Motivasi & 0,816 & 0,60 & Reliabel \\
\hline Kinerja karyawan & 0,784 & 0,60 & Reliabel \\
\hline
\end{tabular}

Tabel 4. Hasil uji reliabilitas kepemimpinan (X1), motivasi (X2), kinerja karyawan (Y). Sumber: Hasil Olah Data SPSS 20

Berdasarkan tabel 4, dijelaskan bahwa hasil pengujian menunjukkan bahwa variabel kepemimpinan (X1), motivasi (X2), kinerja karyawan (Y) dinyatakan reliabel. Hal itu dibuktikan dengan masing-masing variabel memiliki nilai cronbach alpha lebih besar dari 0,60 . 


\section{Uji Koefisien Korelasi}

\begin{tabular}{|l|r|r|r|c|}
\hline \multicolumn{5}{|c|}{ Model Summary } \\
\hline Model & $\mathbf{R}$ & R Square & $\begin{array}{c}\text { Adjusted R } \\
\text { Square }\end{array}$ & $\begin{array}{c}\text { Std. Error of the } \\
\text { Estimate }\end{array}$ \\
\hline 1 & $.458^{\mathrm{a}}$ & .210 & .196 & 4.58317 \\
\hline
\end{tabular}

a. Predictors: (Constant), Kepemimpinan $X_{1}$

Tabel 5. Hasil uji variabel kepemimpinan (X1). Sumber: Hasil Olah Data SPSS 20

Berdasarkan penghitungan tabel 5, koefisien korelasi diperoleh nilai 0,458 , artinya terdapat hubungan yang sedang antara kepemimpinan terhadap kinerja karyawan.

\begin{tabular}{|l|r|r|r|c|}
\hline Model & $\mathbf{R}$ & R Square & $\begin{array}{c}\text { Adjusted R } \\
\text { Square }\end{array}$ & $\begin{array}{c}\text { Std. Error of the } \\
\text { Estimate }\end{array}$ \\
\hline 1 & $.440^{\mathrm{a}}$ & .194 & .179 & 4.62911 \\
\hline
\end{tabular}

a. Predictors: (Constant), Motivasi $X_{2}$

Tabel 6. Hasil uji variabel motivasi (X2). Sumber: Hasil Olah Data SPSS 20

Berdasarkan penghitungan tabel 6, terdapat hubungan yang sedang antara motivasi koefisien korelasi diperoleh nilai 0,440, artinya terhadap kinerja karyawan.

\begin{tabular}{|l|r|r|r|c|}
\hline Model & \multicolumn{1}{|c|}{ Model Summary } \\
\hline 1 & R Square & $\begin{array}{c}\text { Adjusted R } \\
\text { Square }\end{array}$ & $\begin{array}{c}\text { Std. Error of the } \\
\text { Estimate }\end{array}$ \\
\hline
\end{tabular}

a. Predictors: (Constant), Motivasi $X_{2,}$ Kepemimpinan $X_{1}$

Tabel 7. Hasil uji variabel kepemimpinan (X1), motivasi (X2). Sumber: Hasil Olah Data SPSS 20

Berdasarkan penghitungan tabel 7 , koefisien korelasi diperoleh nilai 0,516 yang artinya terdapat hubungan yang sedang antara

\section{Uji Regresi Sederhana dan Regresi Berganda}

Coefficients $^{\mathrm{a}}$

\begin{tabular}{|c|c|c|c|c|c|}
\hline \multirow[t]{2}{*}{ Model } & \multicolumn{2}{|c|}{ Unstandardized Coefficients } & \multirow{2}{*}{$\begin{array}{c}\text { Standardized } \\
\text { Coefficients } \\
\text { Beta }\end{array}$} & \multirow[t]{2}{*}{$\mathrm{t}$} & \multirow[t]{2}{*}{ Sig. } \\
\hline & B & Std. Error & & & \\
\hline (Constant) & 20.007 & 4.273 & & 4.682 & .000 \\
\hline $\mathrm{X} 1$ & .448 & .117 & .458 & 3.823 & .000 \\
\hline
\end{tabular}

a. Dependent Variable: Kinerja Karyawan $Y$ kepemimpinan dan motivasi terhadap kinerja karyawan. 
Tabel 8. Hasil uji regresi sederhana kepemimpinan (X1). Sumber: Hasil Olah Data SPSS 20

Berdasarkan tabel 8, dijelaskan hasil penghitungan diperoleh persamaan regresi $\mathrm{Y}=20,007+0,448 \mathrm{X} 1$, yang artinya terdapat pengaruh positif antara kepemimpinan terhadap kinerja karyawan. Nilai konstanta sebesar 20,007 diartikan bahwa jika variabel kepemimpinan tidak ada, maka telah terdapat nilai kinerja karyawan sebesar 20,007 poin. Nilai koefisien regresi kepemimpinan sebesar 0,448 diartikan 1 unit pada variabel kepemimpinan akan mengakibatkan terjadinya perubahan pada kinerja karyawan sebesar 0,448 poin.

Coefficients $^{\mathrm{a}}$

\begin{tabular}{|c|c|c|c|c|c|}
\hline \multirow[t]{2}{*}{ Model } & \multicolumn{2}{|c|}{ Unstandardized Coefficients } & \multirow{2}{*}{$\begin{array}{l}\text { Standardized } \\
\text { Coefficients } \\
\text { Beta }\end{array}$} & \multirow[t]{2}{*}{$\mathrm{t}$} & \multirow[t]{2}{*}{ Sig. } \\
\hline & B & Std. Error & & & \\
\hline (Constant) & 23.198 & 3.619 & & 6.410 & .000 \\
\hline $\mathrm{X} 2$ & .374 & .103 & .440 & 3.638 & .001 \\
\hline
\end{tabular}

a. Dependent Variable: Kinerja Karyawan $Y$ Tabel 9. Hasil uji regresi sederhana motivasi (X2). Sumber: Hasil Olah Data SPSS 20

Berdasarkan tabel 9, dijelaskan hasil penghitungan diperoleh persamaan regresi $\mathrm{Y}=23,198+0,374 \mathrm{X} 2$, yang artinya terdapat pengaruh positif antara motivasi terhadap kinerja karyawan. Nilai konstanta sebesar 23,198 diartikan bahwa jika variabel motivasi tidak ada, maka telah terdapat nilai kinerja karyawan sebesar 23,198 poin. Nilai koefisien regresi motivasi sebesar 0,374 diartikan 1 unit pada variabel motivasi akan mengakibatkan terjadinya perubahan pada kinerja karyawan sebesar $\quad 0,374$ poin.

Coefficients $^{a}$

\begin{tabular}{|c|c|c|c|c|c|c|}
\hline \multirow{2}{*}{\multicolumn{2}{|c|}{ Model }} & \multicolumn{2}{|c|}{ Unstandardized Coefficients } & \multirow{2}{*}{$\begin{array}{c}\text { Standardized } \\
\text { Coefficients } \\
\text { Beta }\end{array}$} & \multirow[t]{2}{*}{$t$} & \multirow[t]{2}{*}{ Sig. } \\
\hline & & B & Std. Error & & & \\
\hline \multirow{3}{*}{1} & (Constant) & 16.892 & 4.427 & & 3.816 & .000 \\
\hline & $\mathrm{X} 1$ & .307 & .133 & .314 & 2.309 & .025 \\
\hline & $\mathrm{X} 2$ & .236 & .116 & .278 & 2.040 & .046 \\
\hline
\end{tabular}

a. Dependent Variable: Kinerja Karyawan $Y$

Tabel 10. Hasil uji regresi berganda kepemimpinan (X1) motivasi (X2). Sumber: Hasil Olah Data SPSS

Berdasarkan tabel 10, diperoleh persamaan regresi $\mathrm{Y}=16,892+0,307 \mathrm{X} 1+0,236 \mathrm{X} 2$ yang artinya terdapat pengaruh positif antara kepemimpinan dan motivasi terhadap kinerja karyawan. Nilai konstanta sebesar 16,892 diartikan bahwa jika variabel kepemimpinan dan motivasi tidak ada maka terdapat nilai kinerja karyawan sebesar 16,892 poin. Nilai kepemimpinan 0,307 diartikan apabila nilai konstanta tetap dan tidak ada perubahan pada variabel motivasi, maka setiap perubahan 1 unit pada variabel kepemimpinan akan mengakibatkan terjadinya perubahan pada kinerja karyawan sebesar 0,307 poin. Nilai motivasi 0,236 diartikan apabila konstanta tetap dan tidak ada perubahan pada variabel kepemimpinan, maka setiap perubahan 1 unit pada variabel motivasi, akan mengakibatkan perubahan pada kinerja karyawan sebesar 0,236 poin. 


\section{Uji Koefisien Determinasi}

Model Summary

\begin{tabular}{|l|r|r|r|c|}
\hline Model & R & R Square & \multicolumn{1}{|c|}{$\begin{array}{c}\text { Adjusted R } \\
\text { Square }\end{array}$} & $\begin{array}{l}\text { Std. Error of the } \\
\text { Estimate }\end{array}$ \\
\hline 1 & $.458^{\mathrm{a}}$ &. $\mathbf{2 1 0}$ & .196 & 4.58317 \\
\hline
\end{tabular}

a. Predictors: (Constant), Kepemimpinan $X_{1}$

Tabel 11. Hasil uji koefisien determinasi kepemimpinan (X1). Sumber: Hasil Olah Data SPSS 20

Berdasarkan tabel 11, diperoleh nilai Rsquare sebesar 0,210 maka dapat disimpulkan bahwa variabel kepemimpinan berpengaruh terhadap variabel kinerja karyawan sebesar 21 persen, sedangkan sisanya 79 persen dipengaruhi faktor lain.

\begin{tabular}{|l|r|r|r|c|}
\hline Model & $\mathrm{R}$ & R Square & $\begin{array}{c}\text { Adjusted R } \\
\text { Square }\end{array}$ & $\begin{array}{c}\text { Std. Error of the } \\
\text { Estimate }\end{array}$ \\
\hline 1 & $.440^{\mathrm{a}}$ & .194 & .179 & 4.62911 \\
\hline
\end{tabular}

a. Predictors: (Constant), Motivasi $X_{2}$

Tabel 12. Hasil uji koefisien determinasi motivasi (X2). Sumber: Hasil Olah Data SPSS 20

Berdasarkan tabel 12, diperoleh nilai Rsquare sebesar 0,194 maka dapat disimpulkan bahwa variabel motivasi berpengaruh terhadap variabel kinerja karyawan sebesar 19,4 persen, sedangkan sisanya 80,6 persen dipengaruhi faktor lain.

Model Summary

\begin{tabular}{|l|r|r|r|c|}
\hline Model & \multicolumn{1}{|c|}{$\mathrm{R}$} & R Square & \multicolumn{1}{|c|}{$\begin{array}{l}\text { Adjusted R } \\
\text { Square }\end{array}$} & $\begin{array}{l}\text { Std. Error of the } \\
\text { Estimate }\end{array}$ \\
\hline 1 & $.516^{\mathrm{a}}$ & .266 & .239 & 4.45685 \\
\hline
\end{tabular}

a. Predictors: (Constant), Motivasi $X_{2}$, Kepemimpinan $X_{1}$

Tabel 13. Hasil uji koefisien determinasi kepemimpinan (X1), motivasi (X2). Sumber: Hasil Olah Data SPSS 20

Berdasarkan tabel 13, diperoleh nilai Rsquare sebesar 0,266 maka dapat disimpulkan bahwa variabel kepemimpinan dan motivasi berpengaruh terhadap variabel kinerja karyawan sebesar 26,6 persen, sedangkan sisanya 73,4 persen dipengaruhi faktor lain.

\section{Uji Hipotesis}

Coefficients $^{a}$

\begin{tabular}{|c|c|c|c|c|c|}
\hline \multirow[t]{2}{*}{ Model } & \multicolumn{2}{|c|}{ Unstandardized Coefficients } & \multirow{2}{*}{$\begin{array}{l}\text { Standardized } \\
\text { Coefficients } \\
\text { Beta }\end{array}$} & \multirow[t]{2}{*}{$t$} & \multirow[t]{2}{*}{ Sig. } \\
\hline & B & Std. Error & & & \\
\hline (Constant) & 20.007 & 4.273 & & 4.682 & .000 \\
\hline $\mathrm{X} 1$ & .448 & .117 & .458 & 3.823 & .000 \\
\hline
\end{tabular}




\section{a. Dependent Variable: Kinerja $Y$}

Tabel 14. Hasil uji signifikan (t) kepemimpinan (X1). Sumber: Hasil Olah Data SPSS 20

Berdasarkan tabel 14, diperoleh nilai $\mathrm{t}$ hitung > r-tabel atau $(3,823>1,673)$, hal tersebut diperkuat dengan nilai $\rho$ value $<$ sig. 0,05 atau $(0,000<0,05)$. Dengan demikian H01 ditolak dan Ha1 diterima. Hal ini menunjukkan bahwa terdapat pengaruh positif dan signifikan secara parsial antara kepemimpinan terhadap kinerja karyawan.

Coefficients $^{a}$

\begin{tabular}{|c|c|c|c|c|c|c|}
\hline \multirow{2}{*}{\multicolumn{2}{|c|}{ Model }} & \multicolumn{2}{|c|}{ Unstandardized Coefficients } & \multirow{2}{*}{$\begin{array}{c}\begin{array}{c}\text { Standardized } \\
\text { Coefficients }\end{array} \\
\text { Beta }\end{array}$} & \multirow[t]{2}{*}{$\mathrm{t}$} & \multirow[t]{2}{*}{ Sig. } \\
\hline & & B & Std. Error & & & \\
\hline \multirow{2}{*}{1} & (Constant) & 23.198 & 3.619 & & 6.410 & .000 \\
\hline & $\mathrm{x} 2$ & .374 & .103 & .440 & 3.638 & .001 \\
\hline
\end{tabular}

a. Dependent Variable: Kinerja $Y$

Tabel 15. Hasil uji signifikan (t) motivasi (X2). Sumber: Hasil Olah Data SPSS 20

Berdasarkan tabel 15 , diperoleh nilai thitung > r-tabel atau $(3,638>1,673)$, hal tersebut diperkuat dengan nilai $\rho$ value $<$ sig. 0,05 atau $(0,000<0,05)$. Dengan demikian H02 ditolak dan Ha2 diterima. Hal ini menunjukkan bahwa terdapat pengaruh positif dan signifikan secara parsial antara motivasi terhadap kinerja karyawan.

ANOVA $^{\mathrm{a}}$

\begin{tabular}{|rl|r|r|r|r|r|}
\hline Model & & Sum of Squares & df & Mean Square & F & Sig. \\
\hline & Regression & 389.616 & 2 & 194.808 & $\mathbf{9 . 8 0 7}$ & $\mathbf{. 0 0 0 ^ { \mathrm { b } }}$ \\
& Residual & 1072.629 & 54 & 19.864 & & \\
& Total & 1462.246 & 56 & & & \\
\hline
\end{tabular}

a. Dependent Variable: Kinerja $Y$

b. Predictors: (Constant), Motivasi $X_{2}$, Kepemimpinan $X_{1}$

Tabel 16. Hasil uji simultan (F) kepemimpinan (X1), motivasi (X2). Sumber: Hasil Olah Data SPSS 20

Berdasarkan tabel 16, diperoleh nilai Fhitung > F-tabel atau $(9,807>2,780)$, hal ini juga diperkuat dengan nilai $\rho$ value $<$ sig. 0,05 atau $(0,000<0,05)$. Dengan demikian maka H0

\section{KESIMPULAN}

Berdasarkan uraian di atas dan hasil analisis, serta pembahasan, maka kesimpulannya adalah:

1. Terdapat pengaruh positif dan signfikan antara kepemimpinan terhadap kinerja karyawan di Departement Food \& Beverage Hotel Aryaduta Lippo Village Tangerang. ditolak dan $\mathrm{H} 3$ diterima. Hal ini menunjukkan bahwa terdapat pengaruh secara simultan antara kepemimpinan dan motivasi terhadap kinerja karyawan. 


\section{DAFTAR PUSTAKA}

Andi, Supangat. 2011. Statistik Dalam Kajian Deskriptif, Inferensi, dan Nonparametrik. Jakarta : Kencana Prenada Media Group.

Anwar Prabu Mangkunegara. 2015. Sumber Daya Manusia Perusahaan. Cetakan-12. Bandung : Remaja Rosdakarya.

Amirullah. 2015. Pengantar Manajemen. Jakarta : Mitra Wacana Media.

Arda, Mutia (2017) Pengaruh Kepuasan Kerja Dan Disiplin Kerja Terhadap Kinerja Karyawan Pada Bank Rakyat Indonesia Cabang Putri Hijau Medan. Universitas Muhammadiyah Sumatera Utara. Vol. 13 No. 1 ISSN. 2580-4170.

Azwar Saifuddin, 2017. Metode Penelitian Psikologi. Yogyakarta : Pustaka Pelajar.

Cascio, Wayne F. 2017. Managing Human Resources. Colorado : MC Graw - Hill.

Cleopatra (2015). Pengaruh Disiplin Kerja Terhadap Kinerja Karyawan Pada Pabrik Kerupuk Naga Mas Pematangsiantar Jurnal Sultanist Vol. 3 No. 1.

Edy Sutrisno. 2014. Manajemen Sumber Daya Manusia. Cetakan-6. Jakarta : Pranada Media Group.

Edy Sutrisno. 2016. Manajemen Sumber Daya Manusia. Cetakan-8. Jakarta : Pranada Media Group.

Feriyanto, Andri dan Shyta, Endang Triana. 2015. Pengantar Manajemen (3 in 1). Kebumen : Mediatera.

Fernanda, Rahardia (2016). Pengaruh Kompensasi, Kepuasan Kerja, Motivasi Kerja, Dan Gaya Kepemimpinan Terhadap Kinerja Karyawan pada UMKM didesa Wisata Bobung Gunungkidul Yogyakarta. Universitas Negeri Yogyakarta. Vol. 5 No. 2 ISSN. 2502-5430

Gibson. 2017. Organization, Behavior, Structure \& Process, Edition 10. Boston USA.

Gunawan, Lenny (2018). Pengaruh Gaya Kepemimpinan Demokratis Terhadap Kinerja Karyawan. Universitas Ciputra. Vol. 3 No. 3 ISSN. 2527-4635.

Handoko, T. Hani. 2012. Manajemen Personalia dan Sumber Daya Manusia. Yogyakarta : BPFE.

Hamalik Oemar, 2017. Kurikulum dan Pembelajaran. Jakarta : Bumi Aksara.

Hasibuan Malayu S.P. 2012. Manajemen Sumber Daya Manusia. Jakarta : PT. Bumi Aksara.

Hasibuan, Malayu S.P. 2014. Manajemen Sumber Daya Manusia. Edisi Revisi. Jakarta : PT. Bumi Aksara.
Hasibuan, Malayu S.P. 2016. Manajemen Sumber Daya Manusia. Edisi Revisi. Jakarta : Salemba Empat.

Hasibuan, Malayu S.P. 2017. Manajemen Sumber Daya Manusia. Edisi Revisi. Jakarta : PT. Bumi Aksara.

Indra Marjaya dan Fajar Pasaribu (2019). Pengaruh Kepemimpinan, Motivasi,Dan Pelatihan Terhadap Kinerja Karyawan Di PDAM Tirta Deli Kab. Deli Serdang. Universitas Muhammadiyah Sumatera Utara.Vol. 2 No. 1 ISSN 2623-2634.

Nawawi, Hadari dalam Gaol. 2014. A to $Z$ Human Capital (Manajemen Sumber Daya Manusia) Konsep, Teori, dan Pengembangan dalam Konteks Organisasi Publik dan Bisnis. Jakarta : PT. Gramedia Widiasarana.

Pabundu Tika. 2014. Budaya Organisasi dan Peningkatan Kinerja Karyawan. Jakarta : Bumi Aksara.

Priyatno, Duwi. 2012. Cara Kilat Belajar Analisis Data Dengan SPSS 20. Yogyakarta : Andi Offset.

Priyanto, Wahyu Budi (2016). Pengaruh Gaya Kepemimpinan Transformasional Dan Kompensasi Terhadap Kinerja Karyawan Dengan Motivasi Sebagai Variabel Intervening Pada Industri Alas Kaki PT. Bo Kyung Pasuruan. Universitas Muhammadiyah Malang. Vol. 7 No. 2 ISSN. 2580-9431.

Robbins, Stephen P. dan Mary Coulter. 2016. Manajemen, Jilid 1 Edisi 13, Alih Bahasa : Bob Sabran dan Devri Bardani P, Jakarta : Erlangga.

Sadili Samsudin. 2013. Manajemen Sumber Daya Manusia. Bandung : Pustaka Setia.

Sadili Samsudin. 2017. Manajemen Sumber Daya Manusia. Bandung : Pustaka Setia.

Sumaki, Windi (2015). Pengaruh Disiplin Kerja Budaya Organisasi, Dan Komunikasi Terhadap Kinerja Karyawan PT. PLN (Persero) Wilayah Suluttenggo Area Manado. Universitas Sam Ratulangi. Vol. 3 No.3

Salman, et.al. 2011. Leadership Styles And Employee Performance (A Case Study Of Shakarganj Mills Limited Jhang Pakistan). Interdisciplinary Journal of Contemporary Research In Business, Vol. 3, No. 6.

Salutondok, Yohanis (2015). Pengaruh Kepemimpinan, Motivasi, Kondisi Kerja, Dan Disiplin Terhadap Kinerja Pegawai Di Kantor Sekretariat DPRD Kota Sorong. Universitas Sam Ratulangi Manado. Vol. 3 No. 3. 
Sedarmayanti. 2015. Manajemen Sumber Daya Manusia. Bandung : Refika Aditama.

Soekarso, et.al. 2012. Teori Kepemimpinan. Jakarta : Mitra Wacana Media.

Sugiyono. 2012. Meode Penelitian Bisnis. Bandung : PT. Alfabeta.

Sugiyono. 2013. Metode Penelitian Pendidikan Pendekatan Kuantitatif, Kualitatif dan R\&D. Bandung : PT. Alfabeta.

Sugiyono. 2014. Memahami Penelitian Kualitatif. Bandung : PT. Alfabeta.

Sugiyono. 2015. Metode Penelitian Kombinasi (Mix Methods). Bandung : PT. Alfabeta

Sugiyono. 2016. Metode Penelitian Kuantitatif, Kualitatif dan R\&D. Bandung : PT. Alfabeta.
Sugiyono. 2017. Metode Penelitian Kualitatif, Untuk penelitian yang bersifat : eksploratif, enterpretif, interaktif, dan konstruktif. Bandung : PT. Alfabeta.

Thoha, Miftah. 2010. Kepemimpinan Dalam Manajemen. Jakarta : PT. Raja Grafindo Persada.

Thoha, Miftah. 2015. Kepemimpinan Dalam Manajemen. Cetakan-18. Jakarta : PT. Rajagrafindo Persada.

Wibowo. 2016. Manajemen Kinerja. Edisi Kelima. Jakarta : PT. Grafindo Persada.

Wibowo. 2017. Manajemen Kinerja. Edisi Kelima. Depok : PT. Raja Grafindo. 